\title{
EVALUATION AND INVESTIGATION: THE DETERMINANTS OF CENTRAL BANKING EFFICIENCY
}

\author{
Qaiser Farooq Dar ${ }^{1}$, Ahn Young-Hyo ${ }^{1, *}$ and Gulbadin Farooq Dar ${ }^{2}$
}

\begin{abstract}
The stochastic frontier analysis is a comprehensive and accepted approach for analysing efficiency in case of the parametric functional relationship existing between production processes' inputs with its output. Usually, in the banking industry, the relationship between the user inputs and outputs are non-deterministic. In the present study, an SFA approach is used to estimate the efficiency of top 17 Asian central banks in combining three inputs and one output. Structural equation modelling is applied to examine the impact of the country's international trade and economic growth on its central bank efficiency. Based on the results, we have observed significant efficiency ranks between the year 20162018. The technical efficiency value estimates by SFA method range from 0.236822 to 0.821864 . Our calculations also suggest a positive impact of international trade on central bank efficiency compared to the economic growth of that country.
\end{abstract}

Mathematics Subject Classification. 90B30, 90B50, 91B60.

Received November 19, 2020. Accepted February 3, 2021.

\section{INTRODUCTION}

The central banks are government agencies that regulate their national currencies to maintain a country's healthy economic and financial environment. This central financial institution of the nation can be considered the engine of the economy, like an engine it can control and regulate the economic and development functions. Any malfunction in the engine creates a risk for the economic system of the nation. Therefore, the central bank plays an essential role in the nation's economic system by doing different financial functions. The central bank functions are dynamic and dependent on the country's economic and international trade strategy. Thus total volume export, import, GDP, and AER of any country profoundly impact its central bank efficiency. This paper focuses on assessing central bank efficiency by using SFA and examining the impact of international trade and economic growth on central bank efficiency.

Over the past decades, efficiency analysis using frontier methods has become very widespread in the highly completive and rapidly changing business world. The frontier analysis allows the multiple homogeneous types of inputs and outputs in the efficiency estimation. It provides benchmark information against which competitors can identify "best practices" and "worst practices" associated with high and low efficiency. The methodology

Keywords. Stochastic frontier analysis, structural equation modelling, central bank efficiency, international trade, economic growth.

1 Division of International Trade, Institute of Digital Economy, Incheon National University, Incheon 22012, South Korea.

2 Department of Statistics, Ramanujan School of Mathematical Sciences, Pondicherry University, Puducherry 605014, India.

* Corresponding author: yhahn@inu.ac.kr 
of frontier analysis is highly dependent upon the functional relationship between the inputs and outputs. Data envelopment analysis (DEA) is applicable when inputs and outputs of a decision-making unit (DMU) are given, fixed, definite and having a deterministic relationship, which is not possible in general since frontier analysis is based on the estimation of production frontier approach and requires an explicit a priori determination of relationships between output and inputs, like other traditional procedures of efficiency using production functions. Thus, the DEA methodology fails to capture the efficiency analysis in the non-deterministic functional relationship between the inputs and outputs and random shocks in the production processes. In such type of situations, SFA is a powerful technique to estimate the parameters of the production frontier and measure the efficiency of DMU.

The efficiency of any production processes is calculated directly from its output which has functional form with its inputs and has strongly depended on available structural relation of its inputs and output. Thus, any direct/moderating or indirect/meditating effect on the structural association on its inputs and output can change the production processes' frontier and efficiency. The SEM is a multivariate statistical analysis technique used to analyse the association between inputs \& production and examine the factors directly or indirectly associated with its structural relationship. This study's contribution is to measure the efficiency of the central bank in the case of top Asian countries by using SFA. SEM is also applied to examine associated factors that affect the structural relationship of efficiency with its inputs and output. The estimation of directly and indirectly impact international trade and economic growth of the country on the central bank efficiency is also an essential aspect of this study.

The rest of this paper is organized as follows: Section 2 briefly pieces of literature review on the concept of SFA technical efficiency (TE), the methods that are frequently used to measure effectiveness and evaluation of direct \& indirect impact of international trade and economic growth on the functions of a central bank. The stepwise procedure of SFA and SEM methodology are discussed in Section 3. Section 4 describes the data used and SFA analysis, results, and discussion; Section 5 provides some concluding remarks.

\section{LiteratuRE REVIEW}

The main job of a central bank is to supervise a country's financial and banking functions by overseeing all the international moments of trade and conducting monetary policy to promote price stability and sustainable growth of the country. Thus efficiency analysis in case of central banks is the most fascinating and same time it is challenging aspect because of the different policy system. The central banking structure and policy efficiency and macroeconomic performance are given in [8] and explore the empirical relationship between the economic outcomes and monetary policy framework. Nevertheless, we have selected the identical type inputs and commonly available outputs. There are many questions about the central bank efficiency; like what is central bank efficiency and how can measure it discussed in [6]. Central bank efficiency is a reasonably abstract concept that encapsulates several areas ranging from the roles that are appropriate for central banks to perform, to cost efficiency in a narrower sense proposed by Heikensten [20]. DEA and stochastic frontier regression (SFR) applied for the measurement of operational efficiency in a sample of 32 central banks see McKinley and Banaian [28] for the year 2001. Estimation of cost, profit efficiency analysis and managerial behaviour of banks in nine central and eastern European countries during 1995-2002, by using SFA was given by Rossi et al. [30]. The Ihaddaden [22] has discussed a radial DEA approach to measure the Euro-system central bank efficiency. The stochastic frontier specification of the gravity model given in [29] is used on a panel data set of bilateral exports from 17 Western European countries to identify the efficiency of trade integration relative to maximum potential levels.

The concept of efficiency evaluation started with the work of Farrell [16] and was later introduced more formally by Leibenstein [26] in what he called X-(in) efficiency theory. SFA is a parametric approach based on the production function methodology for estimating the efficiency and productivity of a production process was independently proposed by Aigner [2] and Meeusen and Broeck [27]. A stochastic frontier production function model for panel data was submitted by Battese and Coelli [4], in which the sound effects are an exponential function of time. The inefficiency effects are assumed to be independently distributed as truncations of normal 
distributions with constant variance, but with means which are a linear function of observable variables was given by Battese and Coelli [5]. The computer program which has been written to provide maximum likelihood estimates of the parameters of several stochastic productions and cost functions was given by Coelli [10]. Since then, stochastic frontier models have become popular in the sub field of econometrics. An exciting overview of SFA was presented by Kumbhakar and Lovell [25]. The frontier analysis also allows managers to identify the gap between their actual performance and optimal performance [11].

SFA has been one of the frequently used approaches that permit the separation of inefficiency from stochastic error, assuming similar technology is available to all producers and that observations are independent. However, this second assumption is violated where data are spatial auto-correlated; thus Fusco and Vidoli [18] introduce a spatial stochastic frontier model that allows the controlling of heterogeneity adding, in the model or the error term, contextual variables correlated with inefficiency. The main advantages and disadvantages of various parametric and non-parametric frontier approach, along with the micro and macro application of these approaches were discussed by Assaf and Josiassen [3] and Dar et al. [14]. Most of the benefits of the local MLE approach can be obtained with fewer assumptions and involving much more comfortable, faster and numerically more robust computations, by using non-parametric least-squares methods was shown in [31].

An SFA model named the distance function approach which can accommodate multiple inputs, and various outputs are adopted to calculate efficiency scores [12]. Censored regression technique was applied to determine the influencing factors on banking efficiency in case of China suggested by Xiping and Yuesheng [34]. The investigation of performance and efficiency of Turkish (TR) commercial banking sector by using the non-parametric frontier methodology, DEA and Tobit analysis was given in [19,23]. The flexible cause-effect structure and external variables may affect the efficiency score of the production processes was given by Feng et al. [17]. Globalization is directly or indirectly associated with the performance of the central bank, and there is a positive impact of export and import level of the country on its central bank efficiency investigated by Dar et al. [13,15].

In this study, we are using SEM to measure them directly and indirectly, the impact of total export, total imports, gross domestic product (GDP) and average exchange rate (AER) on the central bank efficiency. SEM is a comprehensive statistical approach to testing hypotheses about relations among observed and latent variables given by Hoyle [21]. Exploratory factor analysis (EFA) is a frequently used multivariate analysis technique in statistics to solve a significant by deriving the direct quartimin rotation is given in [24]. SEM has allowed social scientists to perform path analytic modelling with latent variables, which may turn its statistical power in decision making $[9]$.

\section{ReseARCH METhodology}

In order to estimate the efficiency by stochastic frontier analysis (SFA) model proposed in [4] is used with the MLE estimation technique. The SEM technique is used to test the direct and indirect impact of international trade (export \& import) and economic growth (GDP and AER) on central bank efficiency.

\subsection{Stochastic frontier analysis (SFA)}

SFA technique deals with the functional form of input \& outputs; the functional form can be either of the form production, cost, and profit functions. In this study, we are expressing a single dependent variable as a function of one or more explanatory variables. The mathematical form of production functions can be written as:

$$
q=f\left(x_{1}, x_{2}, x_{3}, \ldots, x_{n}\right)
$$

where $q$ is the dependent variable, $x_{i} ;(i=1,2,3, \ldots, n)$ are explanatory variables and $f($.$) is the function. In$ SFA, we need econometric techniques that can use to estimate the unknown parametric values involved in the function, in order to obtain the efficient frontier. Due to these requirements, SFA becomes more computationally 
demanding than DEA in the field of economics. This approach was used by Ainner and Chu [1] and who consider a Cobb-Douglas production frontier.

$$
\ln q_{i}=X_{i}^{\prime} \beta-u_{i} \quad \forall i=1,2,3, \ldots, n
$$

where $q_{i}$ represent the output of the $i$ th firm, $X_{i}$ is $K \times 1$ vector of inputs; $\beta$ is a vector of unknown parameters and $u_{i}$ is non-negative random variable associated with technical inefficiency. In [2,27], added symmetric random error $v_{i}$ to account for statistical noise and independently proposed but identical stochastic frontier model:

$$
\ln q_{i}=X_{i}^{\prime} \beta+v_{i}-u_{i} \quad \forall i=1,2,3, \ldots, n
$$

where $v_{i}$ symmetric statistical noise and it arises due to inadvertent omission of relevant variables from the vector $X_{i}$ as well as from measurement errors and approximation errors associated with the choice of functional form. The model (3.3) is called an SFA-model because the output values are bounded from above by a random (stochastic) variable $\exp \left(X_{i}^{\prime}, \beta+v_{i}\right)$. The random error $v_{i}$ can be positive or negative in SFA. The model (3.3) is dependence upon the production function and if a production process can produce $q_{i}$ output assessing $X_{i}^{\prime}(i=1,2,3, \ldots, n)$ inputs. Then model $(3.3)$ can be rewritten as:

$$
q_{i}=\exp \left(\beta_{0}+\beta_{i} \ln x_{i}\right) \times \exp \left(v_{i}\right) \times \exp \left(-u_{i}\right) .
$$

In the above model $\exp \left(\beta_{0}+\beta_{i} \ln x_{i}\right)$ is deterministic component, $\exp \left(u_{i}\right)$ is statistical noise and $\exp \left(-u_{i}\right)$ represents the inefficiency in model (3.4). The interpretation of model (3.4) can be shown graphically by plotting the input and output of two firms A and B. Where firm A has used the $x_{A}$ level of input to produce the $q_{A}$ level of the production. In contrast, firm B uses the $x_{B}$ level of input to produce the $q_{B}$ level of output. We assume that there is no inefficiency effect (i.e., if $\left.u_{A}=0 \& u_{B}=0\right)$. Then the frontier outputs are $q_{A}^{*} \cong \exp \left(\beta_{0}+\beta_{1} \ln x_{A}+v_{A}\right)$ and $q_{B}^{*} \cong \exp \left(\beta_{0}+\beta_{1} \ln x_{B}+v_{B}\right)$ for firm $\mathrm{A}$ and $\mathrm{B}$ respectively.

Frontier output for firm A lies above the deterministic component of the production frontier only because the statistical noise effect is positive $\left(v_{A}>0\right)$. In contrast, the frontier output for firm B lies below the deterministic part of $f(x, \beta)=q_{i}^{*}$ because the noise effect is negative (i.e., $\left.v_{B}<0\right)$. It is also be seen from the Figure 1 , that the observed output of firm A lies below the deterministic part of the frontier because the sum of the noise and inefficiency effect is negative (i.e., $v-u<0$ ).

It is also be seen from the Figure 3, that the observed output of firm A lies below the deterministic part of the frontier because the sum of the noise and inefficiency effect is negative (i.e., $v-u<0$ ).

However, it is the observed output tend to lie below the deterministic part of the frontier. However, if the noise effect is positive and more significant than the inefficiency effect $\left(i . e ., q_{i}^{\prime}>\exp \left(x_{i}^{\prime}, \beta\right) \Leftrightarrow \varepsilon_{i} \cong\left(v_{i}-u_{i}\right)>0\right)$ then observed output tend to lie below the deterministic part of the frontier. In order to estimate the technical efficiency of $j$ th-DMU, we have to determine $u_{i} \sim$ some distribution. In generally it is required to assume a distribution of $v_{i}$ (stochastic error) form as:

- Half-Normal distributed: $u_{j} \stackrel{i . i . d}{\sim} N^{+}\left(0 \sigma_{u}\right)$.

- Exponential distribution: $u_{j} \stackrel{i . i . d}{\sim} \exp (\lambda)$.

- Truncated-Normal distributed: $u_{j} \stackrel{i . i . d}{\sim} N^{+}\left(\mu_{u} \sigma_{u}\right)$.

- Gamma-distributed: $u_{j} \stackrel{i . i . d}{\sim} \Gamma\left(m, \sigma_{m}\right)$.

The first two distributions have just a single parameter, are empirically traceable and easy to estimate. The last two distributions have two parameters that make them more flexible and also more challenging to determine. The choice of distribution $u_{i}$ in influences quite strongly a level of technical efficiency (TE) and fewer rankings of DMUs. Under the relatively weak assumption, it is usually possible and appropriate to estimate models using the 


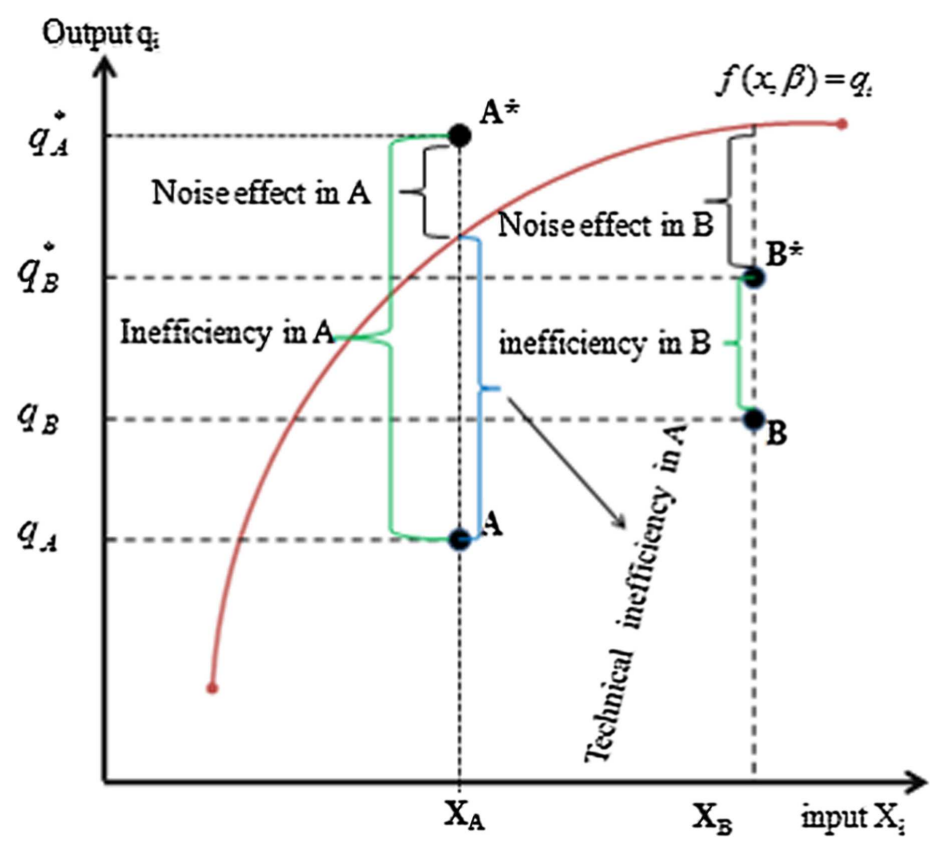

FIGURE 1. Graphically interpretation of SFA.

method of least squares. Slightly stronger distributional assumption allows estimating the unknown parameters using maximum likelihood ${ }^{1}$ or Bayesian techniques ${ }^{2}$ [12]. When decisions about function and distribution must be made, it is recommended to estimate the number of alternative models and to select a preferred model using a likelihood ratio test [10]. Commonly used method for estimation of the stochastic frontier is a maximum likelihood (ML). ML estimations rest on the assumption that the distribution of the errors is known. Battese and Coelli [4] proposed a stochastic frontier production function which is assumed to be distributed as truncated normal random variables. Then technical efficiency $j$ th-DMU is defined as:

$$
\begin{aligned}
\mathrm{TE}_{j, t} & =\frac{q_{j, t}}{\exp \left(\beta_{i} x_{i j}^{\prime}+v_{i, t}\right)}=\frac{\exp \left(\beta_{i} x_{i j}^{\prime}+v_{i, t}-u_{i, t}\right)}{\exp \left(\beta_{i} x_{i j}^{\prime}+v_{i, t}\right)} \\
& =\exp \left(-u_{i, t}\right) \quad \forall(i, j, t) \in(1,2,3, \ldots, n)
\end{aligned}
$$

where $\left(u_{i, t}\right)$ are non-negative and measures as the ratio of actual output to the corresponding potential output (stochastic frontier output) and lies between (0 and 1). The model can be solved by using the concept of linear programming with the objective function of minimizing the sum of the $u_{i}=\ln q_{i}-x_{i} \beta$ subject to $u_{i} \geq 0$. Aigner and Chu suggested in [1] the use of quadratic programming and given a solution as a probabilistic frontier approach. Probabilistic frontier will estimate the frontier by using all the observations in the sample. Then deleting some arbitrary percentage of observation from the sample and make sample firms closest to the frontier. Finally, re-estimate the frontier using the reduced sample and this approach was first used by Timmer [32].

\footnotetext{
${ }^{1}$ Maximum likelihood estimators are popular because they have desirable large sample proprieties.

${ }^{2}$ Bayesian estimation is becoming increasingly popular, not least because it allows obtaining exact finite-sample results concerning nonlinear functions of the parameters.
} 


\subsection{Structural equation modelling (SEM)}

SEM is an extension of the general linear model that allows researchers to determine complex relationships between one or more than one dependent and one or more than one independent variables. Independent variables are usually considered either predictor or causal variables because they predict or cause the dependent variables (response or outcome variables). In SEM, these are generally called exogenous variables (independent) and endogenous (conditional). It combines causal modelling, analysis of covariance structures, confirmatory factor analysis and path analysis (also sometimes called regression). The model also defines whether variables are directly or indirectly measured: manifest variables are measured directly; latent variables are measured indirectly. The two central components of SEM are the path model and the measurement model. The path model or path analysis quantifies specific cause-and-effect relationships between observed variables [33]. At the same time, the measurement model quantifies linkages between hypothetical constructs that might be known but unobservable components of GSCM and observed variables that represent a specific hypothetical construct in the form of a linear combination. The general mathematical formulation of SEM (for the $i$ th unit of $N$ observations)are given in [7] is as below:

$$
y_{i}=\alpha_{i}+\beta x_{i}+\Gamma x_{i}+\zeta_{i}
$$

where $y_{i}$ are latent endogenous(dependent) variables and $x_{i}$ is the latent exogenous (independent) variable. $\alpha$ is an intercept term in the structural model and $\beta$ is structural coefficients of the regression (latent endogenous) to each other. $\Gamma$ is structural coefficients between latent endogenous to exogenous variables and $\zeta$ is structural disturbances/noise (error). We assume that $E\left(\zeta_{i}\right)=0, \operatorname{Cov}\left(\zeta_{i}, \zeta_{j}\right)=0$ and $(1-\beta)$ are invertible.

\section{Data Collection And statistical analysis}

In this section, the stochastic frontier analysis technique is used to assess the central bank efficiency in case of top Asian exporter countries for the three financial years 2016-2018. The data structure has been collected from Bloomberg, central banks annual reports and other national and international economic magazines. According to The Central Intelligence Agency, Population Statistics by Country and International Trade Centre, Trade Map Accessed on August 16, 2019, the list of top Asian exporter countries are shown in Table 1. The data analysis was compiled in Excel, Frontier 4.1, and EMOS software.

In this study, we have used three inputs operating expenses (OE), total investment (TI) and total deposits (TD) where net income (NI) are considered as output for the efficiency evaluation. The unbalanced panel data, which consist of 204 observations, include these three inputs and a single output of 17 central banks for the three years. The average value of all inputs and output are shown in Figure 2. It is observed that the average amount of inputs and output in the year 2017 is higher as compared to 2016 and 2018, as shown in the Figure 2.

The efficiency score is considering as dependent variable for the SEM analysis for estimating the impact of total exports, total imports, GDP and AER on the central efficiency. The average exchange rate (AER) is the mean value of the annual exchange rate against an average value of US\$. Summary statistics of all inputs and output variables are given in Table 2 .

\subsection{Results and discussion}

In this section, we are using frontier model given in [4] for the panel data assumed truncated normal distribution of variables permitted systematically with time as expressed in the model (3.3). Where $u_{i, t}$ are non-negative random variable which is considered to account for the technical inefficiency in production are normally distributed $u_{i, t} \stackrel{i . i . d}{\sim} N^{+}\left(0 \sigma_{u_{i}}^{2}\right)$. In this model, we are using three inputs the maximum like estimators (MLE), standard error (SE), and $t$-ratio of the corresponding parameter is shown in Table 3.

The estimated $\beta$ coefficients for the operating expenses, total investment and total deposits variables are $0.1352,0.1250$ and 0.1704 , respectively. This indicates that all the inputs variable has positively contributed in the overall production. The estimate for the variance parameter $\gamma$ is close to one, which suggests that the 
TABLE 1. List of top 17 Asian exporter countries.

\begin{tabular}{llll}
\hline \hline Rank & Name Country & Name of Central Bank & DMUs \\
\hline 1 & China & People's Bank of China & DMU1 \\
2 & Japan & Bank of Japan & DMU2 \\
3 & South Korea & Bank of Korea & DMU3 \\
4 & Hong Kong & Hong Kong Monetary Authority & DMU4 \\
5 & Singapore & Monetary Authority of Singapore & DMU5 \\
6 & Taiwan & Central Bank of the Republic of China (Taiwan) & DMU6 \\
7 & India & Reserve Bank of India & DMU7 \\
8 & Vietnam & State Bank of Vietnam & DMU8 \\
9 & Thailand & Bank of Thailand & DMU9 \\
10 & Malaysia & Central Bank of Malaysia & DMU10 \\
11 & Indonesia & Bank of Indonesia & DMU11 \\
12 & Turkey & Central Bank of the Republic of Turkey & DMU12 \\
13 & Philippines & Central Bank of the Philippines & DMU13 \\
14 & Kazakhstan & National Bank of Kazakhstan & DMU14 \\
15 & Bangladesh & Bangladesh Bank & DMU15 \\
16 & Pakistan & State Bank of Pakistan & DMU16 \\
17 & Sri Lanka & Central Bank of Sri Lanka & DMU17 \\
\hline
\end{tabular}

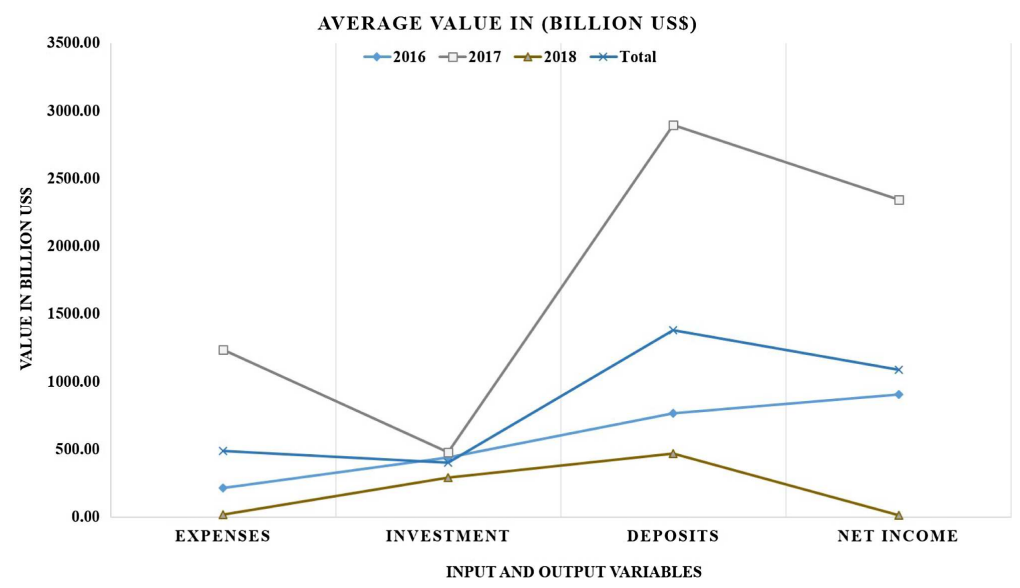

FIGURE 2. Variable comparison of input and output variables.

inefficiency effects are likely to be highly significant in the analysis of the value of the output of the production. The value of log-likelihood function is 0.70133 , and LR test value at one-side error is 0.1156 .

The results of efficiency estimated by the model (3.3) reveal that the mean efficiency for the year 2016 is $0.7855,0.82856$ for the year 2017 and 0.85151 respectively for the year 2018 as shown in Table 4 . The ranks are given as per the efficiency score. There is significant difference in efficiency ranks of DMUs between the year 2016-2017 $(p$-value $=0.000), 2017-2018(p=0.038)$ and $(p=0.025)$ respectively for the year 2016-2018. The average percentage of overall efficiency is $82 \%$ for the year 2016-2018, only DMU2(bank of Japan) has maintained the efficiency of approximately $94 \%$ at first rank. The results of our analysis reveal that DMU3 (Bank of Korea) has maintained the efficiency at 89\% during the year 2016-2018 and having the efficiency rank at 7th position. Whereas, DMU7 (Reserve Bank of India) is operating only $28 \%$ efficiency for the year 2016-17, which increased to $47 \%$ in the year 2018 . 
TABLE 2. Descriptive statistics of variables.

\begin{tabular}{|c|c|c|c|c|}
\hline \multirow[b]{2}{*}{ Variables } & \multicolumn{3}{|c|}{ Median \pm Inter quartile range (in Billion US \$) } & \multirow[b]{2}{*}{$p$-value } \\
\hline & 2016 & 2017 & 2018 & \\
\hline Operation expenses & $5.11 \pm 62.78$ & $5.86 \pm 336.00$ & $3.21 \pm 32.15$ & 0.373 \\
\hline Total investment & $17.07 \pm 320.00$ & $26.78 \pm 4600.00$ & $2.83 \pm 38.92$ & 0.871 \\
\hline Total deposits & 45.631580 .00 & $48.55 \pm 1700.00$ & $72.90 \pm 8.52$ & 0.372 \\
\hline Net income & $2.57 \pm 23.59$ & $2.24 \pm 93.78$ & $4.37 \pm 6.19$ & 0.346 \\
\hline Exports & $173.65 \pm 250.00$ & $1846.30 \pm 265.00$ & $249.81 \pm 426.00$ & 0.606 \\
\hline Imports & $177.46 \pm 193.00$ & $341.45 \pm 994.70$ & $196.81 \pm 371.00$ & 0.959 \\
\hline \multirow[t]{2}{*}{ GDP } & $320.00 \pm 960.00$ & $341.45 \pm 994.70$ & $360.32 \pm 1033.5$ & 0.977 \\
\hline & \multicolumn{3}{|c|}{ Average exchange rate (against US $\$$ ) } & \\
\hline AER & $67.19 \pm 240.66$ & $65.00 \pm 245.00$ & $68.42 \pm 271.48$ & 0.382 \\
\hline
\end{tabular}

TABLE 3. Estimated value of SFA parameter.

\begin{tabular}{llll}
\hline \hline Parameter & Coefficient & Standard-error & $t$-ratio \\
\hline$\beta_{0}$ & 1.4431 & 0.9405 & 1.5342 \\
$\beta_{1}$ & 0.3513 & 0.1352 & 2.5984 \\
$\beta_{2}$ & 0.3043 & 0.125 & 2.4337 \\
$\beta_{3}$ & 0.2762 & 0.1704 & 1.1618 \\
$\sigma^{2}$ & 1.2651 & 0.3845 & 3.2931 \\
$\gamma$ & 0.5617 & 0.1215 & 4.6256 \\
$\mu$ & 1.686 & 0.7171 & 2.3512 \\
$\eta$ & -0.0012 & 0.0771 & -0.0158 \\
\hline
\end{tabular}

TABLE 4. Stochastic Frontier efficiency score and Ranking.

\begin{tabular}{|c|c|c|c|c|c|c|c|c|}
\hline \multirow{2}{*}{ DMUs } & \multicolumn{6}{|c|}{ Year } & \multirow{2}{*}{ Average } & \multirow{2}{*}{ Rank } \\
\hline & 2016 & Rank & 2017 & Rank & 2018 & Rank & & \\
\hline DMU1 & 0.937598 & 4 & 0.93769 & 5 & 0.93719 & 2 & 0.93749 & 2 \\
\hline DMU2 & 0.944081 & 1 & 0.95743 & 1 & 0.94573 & 1 & 0.94908 & 1 \\
\hline DMU3 & 0.892917 & 7 & 0.89036 & 7 & 0.89492 & 6 & 0.89273 & 7 \\
\hline DMU4 & 0.909766 & 6 & 0.93992 & 4 & 0.89083 & 8 & 0.9135 & 6 \\
\hline DMU5 & 0.780043 & 12 & 0.85115 & 10 & 0.85338 & 14 & 0.82819 & 11 \\
\hline DMU6 & 0.942999 & 2 & 0.94219 & 2 & 0.89186 & 7 & 0.92568 & 4 \\
\hline DMU7 & 0.285883 & 17 & 0.23682 & 17 & 0.89067 & 9 & 0.47112 & 17 \\
\hline DMU8 & 0.593543 & 15 & 0.77511 & 15 & 0.34983 & 17 & 0.57283 & 16 \\
\hline DMU9 & 0.793225 & 11 & 0.81181 & 13 & 0.78814 & 16 & 0.79773 & 13 \\
\hline DMU10 & 0.439484 & 16 & 0.66926 & 16 & 0.88595 & 10 & 0.6649 & 15 \\
\hline DMU11 & 0.855427 & 10 & 0.83177 & 11 & 0.85826 & 13 & 0.84849 & 9 \\
\hline DMU12 & 0.873683 & 8 & 0.88244 & 8 & 0.90115 & 5 & 0.88576 & 8 \\
\hline DMU13 & 0.866477 & 9 & 0.87826 & 9 & 0.7885 & 15 & 0.84441 & 10 \\
\hline DMU14 & 0.603585 & 14 & 0.81272 & 12 & 0.87724 & 12 & 0.76452 & 14 \\
\hline DMU15 & 0.763432 & 13 & 0.79412 & 14 & 0.90461 & 4 & 0.82072 & 12 \\
\hline DMU16 & 0.939022 & 3 & 0.9402 & 3 & 0.88573 & 11 & 0.92165 & 5 \\
\hline DMU17 & 0.932752 & 5 & 0.93421 & 6 & 0.93174 & 3 & 0.9329 & 3 \\
\hline Mean & 0.7855 & & 0.82856 & & 0.85156 & & 0.82186 & \\
\hline
\end{tabular}




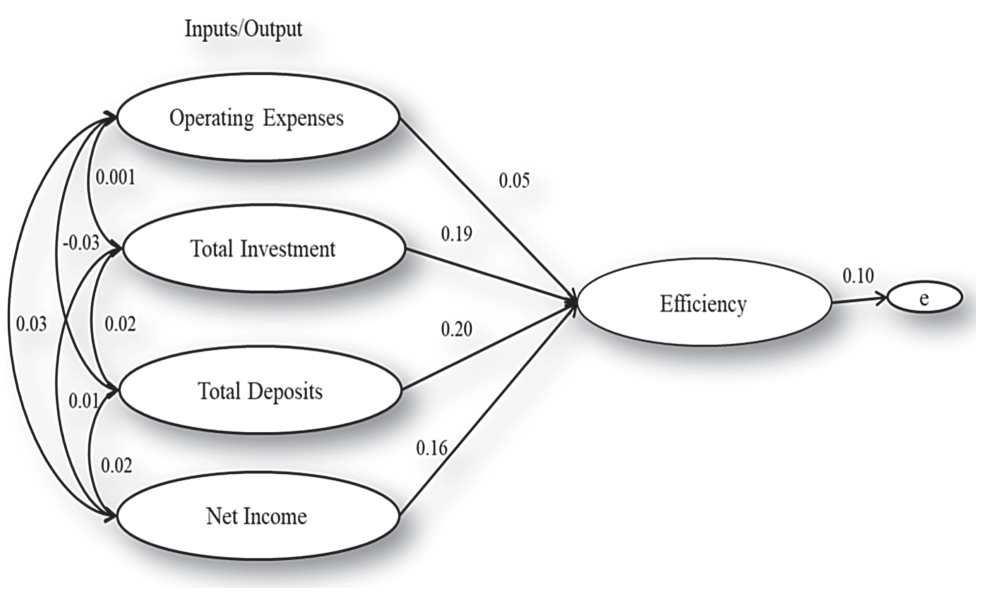

Figure 3. Impact of Inputs and output variables on efficiency.

An efficiency score closes to 1 implies that firms are operating close to the frontier of what is technically possible. The efficiency is rage ranged from $23 \%$ to $95 \%$ with an average of $82 \%$. The DMU1 (People's Bank of China), DMU2 (Bank of Japan), DMU3 (Bank of Korea), DMU4 (Hong Kong Monetary Authority), DMU6 (Central Bank of the Republic of China (Taiwan)), DMU16 (State Bank of Pakistan) and DMU17 (Central Bank of Sri Lanka) are operating more than $90 \%$ of efficiency as shown in Table 4.

\subsubsection{Impact of international trade and economic growth on central efficiency}

In this session, we are evaluating the association of inputs and output with efficiency to estimate the direct and indirect impact of international trade and economic growth on the performance of the central bank. In this scenario, the SEM technique is applied in three different path models for the estimation of association and the impact of variables like import, export, GDP and AER on the efficiency of the central bank.

Model 1. Is a straightforward path model to analyses the association of inputs and output variable with central bank efficiency. The structure of Model 1 is shown in Figure 3, and it was observed from the results that correlation between all inputs and output are positive but insignificant except operating expenses and total deposits which is showing negligible negative correction. On the other side, the direct impact of total deposits is $20 \%$, total investment is $19 \%$, and the effect of net income is $16 \%$, which has positive and significant impact on the central bank efficiency. In comparison, the impact of operating expenses on the performance of the central bank is insignificant but positive. Thus, the effectiveness of the central bank may be increased by the optimal use of total deposit, total investment and net income, which means theses variables are more important than operating expenses.

The aimed objective of this study is to provide the central bank efficiency and estimate the direct and indirect impact of international trade and economic growth on central bank efficiency. In order to evaluate the effects of international trade on central ability, the present study concentrates on the total import \& export volume of the country. Where to determine the impact of economic growth on the central bank efficiency, we have focused on the GDP and annual average exchange against US\$. These variables seem to be much better suited to indicate a country's international trade performance than growth rates exports since its use, on the one hand, avoids the bias of using a component of GDP and it is, on the other hand, a straight forward measure of a country's exposure to international trade.

Model 2. Is a bit complicated then Model 1 and to determine the indirect impact of international trade (volume of imports \& exports) and economic growth (GDP and AER) on the central efficiency of the country. Model 2 to 


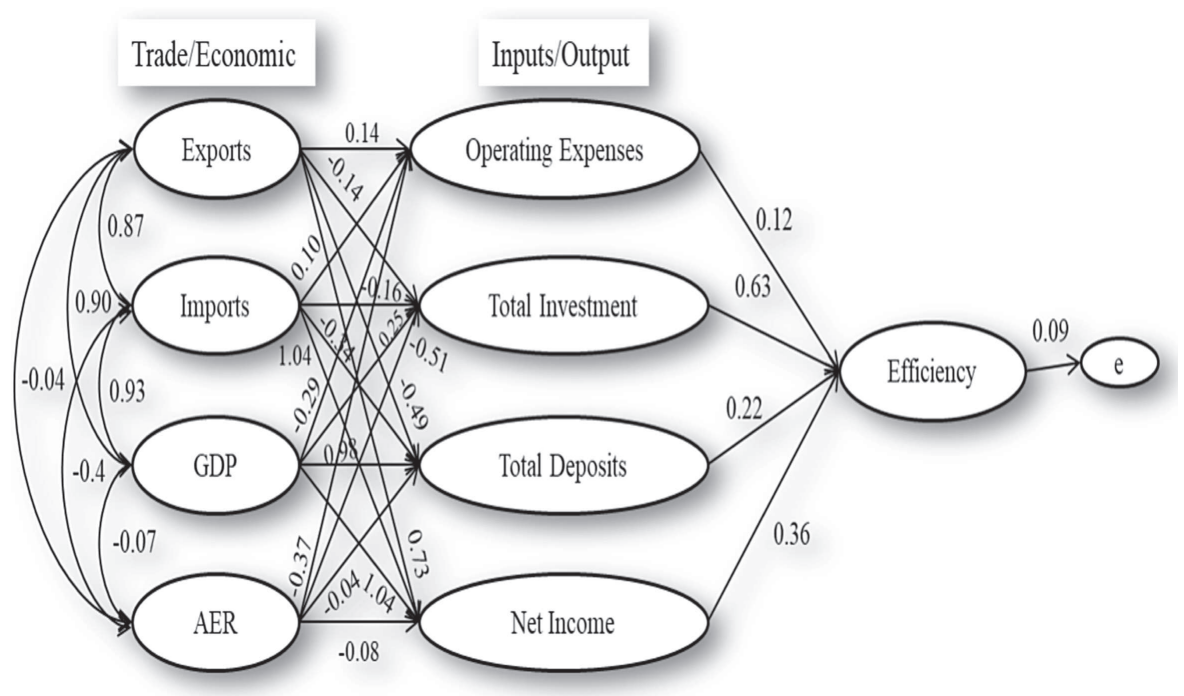

FigURE 4. Indirect impact of trade/economy on central bank efficiency.

estimates the effect of total export, imports, AER and GDP on the inputs (operating expenses, total investment and deposits) and output (net income) of the central bank. The structural path diagram of Model 2 is shown in Figure 4, as given below.

The results of Model 2 revels that the direct and total effect of international trade and economic growth on the central bank efficiency is positive as well as negative. The impacts of international trade on the center bank efficiency are estimated by using the total export and import volume of the country and coefficient of indirect and total effect (C.R. \& TE) of total export and import on operating expenses is (C.R. $=0.139 \&$ TE $=$ 0.359), total investment (C.R. $=-0.138 \& \mathrm{TE}=-0.018)$, total deposits (C.R. $=-0.491, \mathrm{TE}=-0.37)$ and (C.R. $=0.721, \mathrm{TE}=0.841)$ on the net income(output). Whereas the coefficient of indirect and total effect of total import are $(\mathrm{C} . \mathrm{R} .=0.096 \& \mathrm{TE}=1.59),(\mathrm{C} . \mathrm{R} .=-0.164 \& \mathrm{TE}=0.466),(\mathrm{C} . \mathrm{R} .=-0.336, \mathrm{TE}=0.294)$ and $(\mathrm{C} . \mathrm{R} .=1.043, \mathrm{TE}=1.673)$ respectively are showing in the Figure 4.

The impact of economic growth on central bank of efficiency is estimated by use of GDP and AER of the country. The indirect and total effect of GDP on central efficiency are: (C.R. $=-0.290 \& \mathrm{TE}=-0.170$ ) on operating expenses, $\mathrm{TI}(\mathrm{C} . \mathrm{R} .=0.246 \& \mathrm{TE}=0.466)$ on total investment, $\mathrm{TD}(\mathrm{C} . \mathrm{R} .=0.981, \mathrm{TE}=1.101)$ total deposits and $(\mathrm{C} . \mathrm{R} .=-1.716, \mathrm{TE}=-1.595)$ on the net income respectively. On the other side, coefficient of indirect and total effect of by AER on the input and output of central bank efficiency are: (C.R. $=-0.371 \&$ TE $=0.101)$, $(\mathrm{C} . \mathrm{R} .=-0.164 \& \mathrm{TE}=0.466),(\mathrm{C} . \mathrm{R} .=-0.041, \mathrm{TE}=0.342)$ and $(\mathrm{C} . \mathrm{R} .=-0.082, \mathrm{TE}=0.301)$ respectively.

Thus international trade characterized by export and import volume has a statistically significant and positive effect on central bank efficiency mediated by the level of total net income. Therefore, to improve the performance of the central bank, the country should increase the volume of export and import of the country, which results to increase the net income of the central bank. Meanwhile, by increasing the total export volume, the country results to grow in the total deposits which impact positive significant on the performance of the central bank as compare import level of a country. On the other side, GPD has a significant adverse effect on the central bank efficiency mediated by the net income. In contrast, the AER has a negative impact and insignificantly on the inputs and output of the central bank

Model 3. The path and structure of Model 3 are shown in Figure 5. In this model, each of the four latent variables export, import, GDP and average exchange rate represented by on measured variable efficiency. This model aims to estimate the direct effect of latent variables on the measured variable. 


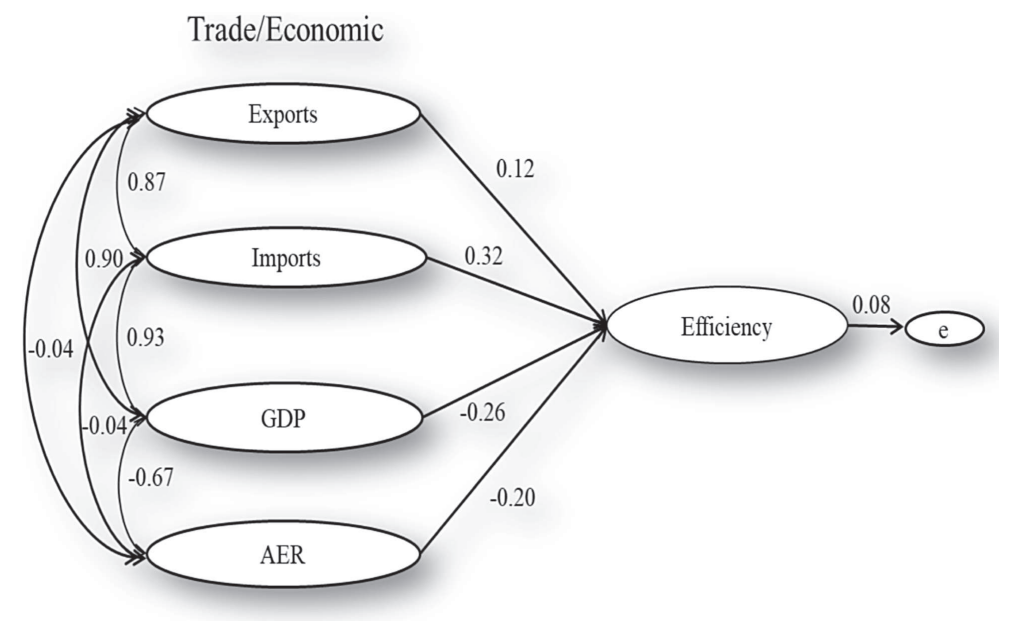

FiguRE 5. Direct impact of trade/economy of central bank efficiency.

TABLE 5. Correlation between the variables.

\begin{tabular}{lllllllll}
\hline \hline Variables & TI & TD & NI & Eff. & Exports & Imports & AER & GDP \\
\hline OE & 0.001 & -0.027 & 0.031 & 0.051 & -0.037 & -0.051 & -0.027 & -0.074 \\
TI & & -0.022 & 0.011 & 0.183 & -0.058 & -0.054 & -0.055 & -0.027 \\
TD & & & -0.022 & 0.194 & 0.098 & 0.149 & -0.037 & 0.23 \\
NI & & & & 0.159 & 0.091 & 0.08 & -0.035 & -0.095 \\
Eff. & & & & & 0.181 & 0.198 & -0.198 & 0.167 \\
Exports & & & & & & $0.869^{* *}$ & -0.041 & $0.897^{* *}$ \\
Import & & & & & & & -0.036 & $0.928^{* *}$ \\
AER & & & & & & & & -0.067 \\
\hline
\end{tabular}

Notes. ${ }^{* *}$ Correlation is significant at the 0.01 level (2-tailed).

The result of Model 3 reveals the coefficient of an indirect effect of total export, total import, GDP and AER on the central bank efficiency are: $0.124,0.324,-0.261$ and -0.201 , respectively. Thus total export and import volume of the country has a significant positive effect of the central bank efficiency as compared to GDP and AER, which impacts negatively. Hence, we have found that international trade impacts positively on central bank productivity as compared to economic growth of country.

Additionally, the results Model 3 also shows that there is a significant positive correlation between exports, imports with GDP and negative with the AER. It is also shown in Table 5; there is a positive correlation between the efficiency of the central bank of the country with the exports, imports and GDP of that country. Whereas, the negative correlation is found between the Central bank efficiency and average exchange rate.

This paper examines the financial efficiency of central banks in case of top 17 Asian exporter countries over the period 2016-2018 by using stochastic frontier analysis. We disentangle efficiency by inputs and outputs and identify the contribution of each input for central bank efficiency. The contribution of total deposits, total investment and net income for the central efficiency are positive and significant. The overall efficiency has a mean score of $82 \%$ and the only bank of Japan has maintained the capability of approximately $94 \%$ at first rank over the period of time. Whereas, Bank of Korea has kept the ability at $89 \%$ and the Reserve Bank of India is operating only $28 \%$ efficiency for over the period of time. 
The People's Bank of China, Bank of Japan, Bank of Korea, Hong Kong Monetary Authority, Central Bank of the Republic of China (Taiwan), State Bank of Pakistan and Central Bank of Sri Lanka are the higher class of efficiency operating average efficiency $92 \%$ taken from the average efficiency over the period of time. The second one is a moderate class of efficiency, with efficiency value ranged from $80 \%$ to $90 \%$. This group including Monetary Authority of Singapore, Bank of Thailand, Bank of Indonesia, Central Bank of the Republic of Turkey, Central Bank of the Philippines and Bangladesh Bank which operating $83 \%$ average efficiency value. The lowefficiency class includes Reserve Bank of India, State Bank of Vietnam, Central Bank of Malaysia and National Bank of Kazakhstan operating the efficiency less $70 \%$ with $62 \%$ average efficiency.

\subsubsection{Limitations of the study and future research}

The study is to estimate the central bank efficiency and examine the direct, indirect impact of international trade and economic growth on the central efficiency. There are several limitations to this study. One of them is, in this study, We have included only the top 17 Asian export countries in our sample. However, future research may conduct on the countries of Asian and world as well. The analysis of central bank efficiency was the primary aim of the study. The selection of inputs and output was a challenging aspect of the study. We have used financial variables: operating expenses, total investment and total deposits as the inputs, whereas the net income as a single output. In future, we may use other financial and operational variables with different techniques of efficiency and frontier analysis. The second aspect of the paper is interesting, where we have examined the direct/indirect impact of international trade and economic growth on the central efficiency of the country. The effect of international trade was estimated by use of total export and import of the country, whereas GDP and AER estimate the impact of economic growth. The other variables may affect central bank efficiency. Thus in future, we may research the selection of variables which may have a significant impact on the central efficiency.

\section{Conclusion}

The evaluation of central efficiency and investigation of its determinants is very challenging task. It can be solved with stochastic frontier analysis and structural equation modelling which has good discrimination power over DEA in penal data with tobit regression analysis. Overall, it can be gathered from the results of this study that the total deposits, total investment and net income have a critical role in the central bank efficiency as compared to the operating expenses. On the other side, the export and import value of the country have a significant impact on the net income. Therefore, in order to improve the performance of the central bank, the country should increase the volume of export and import. Meanwhile, by increasing the total export volume, the country results to grow in the total deposits which impact positive significant on the performance of the central bank as compare import level of the country. Thus total export and import volume of the country has a significant positive effect of the central bank efficiency as compared to GDP and AER. There is found a positive correlation between the effectiveness of the central bank of the country with the export and import of that country. Hence; we conclude that the international trade impacts positively on the central efficiency as compared to the economic growth.

Acknowledgements. The authors wish to acknowledge Incheon National University, Incheon South Korea for providing funding to support the research reported in this paper. The authors are also grateful to an anonymous referee for some very constructive suggestions for improving the paper.

\section{REFERENCES}

[1] D.J. Aigner and S.F. Chu, On estimating the industry production function. Am. Econ. Rev. 58 (1968) 826-839.

[2] D.J. Aigner, C.A.K. Lovell and P. Schmidt, Formulation and estimation of stochastic. Rev. Econ. Stat. 80 (1977) $454-465$.

[3] A.G. Assaf and A. Josiassen, Frontier analysis: a state-of-the-art review and meta-analysis. J. Travel Res. 55 (2016) $612-627$.

[4] G.E. Battese and T.J. Coelli, Frontier production functions, technical efficiency and panel data: with application to paddy farmers in India. J. Prod. Anal. 3 (1992) 153-169. 
[5] G.E. Battese and T.J. Coelli, A model for technical inefficiency effects in a stochastic frontier production function for panel data. Empirical Econ. 20 (1995) 323-332.

[6] M. Blix, S. Daltung and L. Heikensten, On central bank efficiency. Sveriges Riksbank Econ. Rev. 3 (2003) 81-93.

[7] K.A. Bollen and M.D. Noble, Structural equation models and the quantification of behavior. Proc. Nat. Acad. Sci. 108 (2011) 15639-15646.

[8] S.G. Cecchetti and S. Krause, Central bank structure, policy efficiency, and macroeconomic performance: exploring empirical relationships. Rev.-Federal Res. Bank Saint Louis 48 (2002) 47-60.

[9] W.W. Chin, Commentary: issues and opinion on structural equation modeling. JSTOR 22 (1998) 7-16.

[10] T.J. Coelli, A guide to FRONTIER version 4.1: a computer program for stochastic frontier production and cost function estimation. CEPA Working papers 7 (1996) 1-33.

[11] T.J. Coelli, D.S.P. Rao, C.J. O'Donnell and G.E. Battese, An introduction to Efficiency and Productivity Analysis. Springer Science \& Business Media (2005).

[12] T. Coelli, L. Lauwers and G. Van Huylenbroeck, Formulation of technical, economic and environmental efficiency measures that are consistent with the materials balance condition. Centre for Efficiency and Productivity Analysis Working Paper 6 (2005).

[13] Q.F. Dar and A.Y. Hyo, Investigate Central Bank Efficiency and its relation with export level: a case of Top Asian Exporter Countries. Int. Conf. Korean Trade Assoc. 8 (2019) 695-705.

[14] Q.F. Dar, T.R. Padi and A.M. Tali, Decision support system through data envelopment analysis \& stochastic frontier analysis. Int. J. Modern Math. Sci. 15 (2017) 1-13.

[15] Q.F. Dar, Y.H. Ahn and G.F. Dar, Impact of international trade on central bank efficiency: an application of DEA and Tobit Regression Analysis. Stat. Optim. Inf. Comput. 9 (2021) 223-240.

[16] M.J. Farrell, The measurement of productive efficiency. J. R. Stat. Soc.: Ser. A 120 (1957) 253-281.

[17] T. Feng, J. Zhang and A. Fujiwara, Environmental efficiency analysis of transportation system: a stochastic frontier approach with flexible cause-effect structure. Proc. Eastern Asia Soc. Transp. Stud. 7 (2007) 188-288.

[18] E. Fusco and F. Vidoli, Spatial stochastic frontier models: controlling spatial global and local heterogeneity. Int. Rev. Appl. Econ. 27 (2013) 679-694.

[19] H. Gunes and D. Yildirim, Estimating cost efficiency of Turkish commercial banks under unobserved heterogeneity with stochastic frontier models. Central Bank Rev. 16 (2016) 127-136.

[20] L. Heikensten, How to promote and measure central bank efficiency. BIS Rev. 24 (2003) 1-5.

[21] R.H. Hoyle, The Structural Equation Modeling Approach: Basic Concepts and Fundamental Issues. Sage Publications, Inc. (1995).

[22] M.E.F. Ihaddaden, Investigating eurosystem central banking efficiency: a data envelopment analysis approach. Rev. Econ. Gestion 3 (2019) 1-12.

[23] P.M. Jackson, M.D. Fethi and G. Inal, Evaluating the Efficiency of Turkish Commercial Banks: An Application of DEA and Tobit Analysis. University of Leicester Efficiency and Productivity Research Unit (2000).

[24] R.I. Jennrich and P.F. Sampson, Rotation for simple loadings. Psychometrika 31 (1966) 313-323.

[25] S.C. Kumbhakar and C.K. Lovell, Stochastic Frontier Analysis. Cambridge University Press (2003).

[26] H. Leibenstein, Beyond Economic Man. Harvard University Press (1976).

[27] W. Meeusen and J. van Den Broeck, Efficiency estimation from Cobb-Douglas production functions with composed error. Int. Econ. Rev. 18 (1977) 435-444.

[28] V. McKinley and K. Banaian, Central Bank Operational Efficiency: Meaning and Measurement. Central Banking Publications (2005) 44-81.

[29] G. Ravishankar and M.M. Stack, The gravity model and trade efficiency: a stochastic frontier analysis of Eastern European Countries' potential trade. World Econ. 37 (2014) 690-704.

[30] S.P. Rossi, M. Schwaiger and G. Winkler, Managerial behavior and cost/profit efficiency in the banking sectors of Central and Eastern European countries. Working Papers 96 (2005).

[31] L. Simar, I. Van Keilegom and V. Zelenyuk, Non-parametric least-squares methods for stochastic frontier models. J. Prod. Anal. 47 (2017) 189-204.

[32] C.P. Timmer, Using a probabilistic frontier production function to measure technical efficiency. J. Political Econ. 79 (1971) 776-794.

[33] S. Wright, The method of path coefficients. Ann. Math. Stat. 5 (1934) 161-215.

[34] W. Xiping and L. Yuesheng, Banking efficiency in China: application of DEA and Tobit Analysis. In: International Conference of Management Science and Engineering of IEEE (2007). 